that he can rarely avail himself of the resources for the cultivation of efficiency which are said to be within reach of his more favoured brother in the city. Deprived as the great majority of practitioners is by the system of hospital staffing now in vogue of equal means by which practical knowledge of disease, its course and treatment, may be kept alive and developed, is it any wonder that some of us lag behind in our journey along the road of science? Post-graduate courses serve a useful purpose as occasional refreshers, but they cannot supply the pabulum which the practitioner not on the staff stands in lack of. The stimulus should not be applied at long intervals, but should be continuous and constant. There is no dearth of books and journals by which he can make himself acquainted with all that is being said and written, but he cannot see what is being done. He must be put in the way of actually seeing the practical application of all the newest methods of research and treatment; he must be given access to the practice of the local hospital. It may be said that he is free now to see the practice of the hospital of his town, but it must be admitted that there is no system or method in vogue by which the "local professor" can really derive instruction from the large amount of clinical material that is at present positively running to waste. A casual walk round the wards with the visiting staff does not fulfil the necessities of the situation. am in full accord with Dr. Hawthorne in his plea that " the local hospital should take its part in the process of postgraduate education"; it should be a school to the doctors practising within its range of service. No doubt there are various ways in which this proposal could be put into action, but as a beginning $\mathbf{I}$ advocate the weekly demonstration. Each member of the staff should in turn undertake to give an hour of his time on a fixed day to a demonstration of cases, an exposé of some new method of treatment or diagnosis, or, indeed, anything he considers calculated to interest and instruct his audience of fellow practitioners. As Dr. Hawthorne points out, such a scheme would be of great value, not less to the giver than the recipient, and the former might consider that the intellectual benefit accruing to himself a sufficient recompense for his trouble, though I am inclined to think that the payment of a moderate annual fee would remove from the mind of the latter a possible feeling of pressure under obligation. Fees, I am confident, there should be, and if the objections of the staff to receive them could not be overcome the hospital funds should take them.

I have good grounds for believing that the general practitioner is to-day desirous of making himself thoroughly competent in his work, both for his own sake and for the good of his patients, and there is good reason to expect that he will greedily seize upon any suitable opportunities that may be put before him. A teacher is made, not born, and though no doubt some provincial hospital men will receive my suggestion with doubt and diffidence as to their ability to carry it out in their own sphere, I am sanguine in my belief that as practice brings confidence their efforts to rise to the situation will result in their achievement of the desired object. I am, Sir, yours faithfully,

West Mersea, Colchester, Sept. 24th, 1913.

B. HALL.

\section{THE HONYMAN-GILLESPIE TRUST.}

\section{To the Editor of THE LANCET.}

SrR,-I have reason to know that there is a good deal of misunderstanding in the medical profession with regard to the object and working of this trust, and I hope you will allow me, through the medium of THE LANCET, to make the whole position clear.

The late Mrs. Honyman-Gillespie, of Torbane Hill, Scotland, left in 1886 a certain sum of money wherewith to build a medical school where homoopaths could study with regular practitioners, and she added a clause in her will that no vivisectors should benefit by her money. As the first condition presented many difficulties, and also as the legacy was not large enough to found the new school, the judges in court decided that the trustees should allot two-thirds of the income to the foundation of a chair in orthodox medicine and one-third to the foundation of a chair in homceopathy, the provision against vivisection being carried out. The trustees consequently decided to create a lectureship in the regular practice in tropical diseases and to allow the homoopaths to choose their own subject.

The clause with regard to vivisection forbade the trustees to accede to any demands made by the universities or existing medical schools that the lectureship should be attached to them, and it was resolved that some religious institution should be asked to add courses of tropical lectures to their educational syllabus. The Central Body of the Young Men's Christian Association, at 186, Aldersgatestreet, was accordingly chosen, and since 1908 courses of lectures upon tropical medicine have been delivered there every Tuesday afternoon during the winter.

I was asked by the trustees, as I had travelled extensively in the Tropies and had verified the discovery of Laveran's parasite of malarial fever in the Mauritius, ${ }^{1}$ to relinquish my practice in Paris and take up this lectureship, to which is also attached a scholarship in tropical diseases research. The income is about $£ 400$ a year, $£ 300$ sure and another $£ 100$ to defray expenses. I am bound to deliver 40 lectures a year and to devote four hours a day to original research.

In order to reach missionary students in Oxford, Manstield College has appointed me lecturer there, and every two years I deliver a short course of lectures to all who wish to come. The missionary students both in London and in Oxford are admitted free, and all others pay $£ 11 s$. There are generally about 20 to 25 students at the London class; they are principally missionary students and missionaries on furlough, but we always have a few travellers or explorers and prospectors. Professor Cantlie, Professor Daniels, and Professor Newham have lectured to these students, and Sir Ronald Ross is going to take the chair at the opening of this winter session.

My desire to do original research in return for the scholar. ship led me last winter to Chile, Peru, Panama, and the West Indies. I found a new oestrus larva in the sheep's brain in Chile, I studied the verruga and the uta in Peru, and gathered srecimens in the West Indies. Next Januar I hope to proceed to India to study plague and cholera in situ.

I mention all these things not with any intent to magnify my own work, but solely with the desire to make plain to the medical profession what the trust is, and to show that within the restrictions enjoined by the testamentary conditions scientific work of a useful and eminently practical kind is being done. I am, Sir, yours faithfully,

D. E. Anderson, M.D., B.Sc. Lond, M.D. Paris, \&c.

\section{THE GOVERNMENT OPHTHALMIC HOSPITAL, MADRAS. \\ To the Editor of THE LANCET.}

SrR,-D During the recent meetings of the Oxford Ophthalmological Society, of the British Medical Association, and of the International Congress a number of medical men asked if they might visit Madras for the purpose of seeing the work at the Government Ophthalmic Hospital there. I had at that time every intention of returning to Madras at the end of this year, and I told them that I should be glad to welcome them at my clinic. In the meantime my plans have been changed and I am not returning to India for the present at least. Unfortunately, I have not got the names or addresses of a number of those who thus approached me, and am therefore unable to communicate with them direct. I should be extremely sorry if owing to my inadvertence in not taking the names of all such any inconvenience or disappointment arose to a visitor after so long a journey as that to Madras. I shall therefore be greatly obliged if you will give me this opportunity of letting the matter bo known. As a number of those who wished to visit Madras came from India, America, and the continent, I shall be greatly obliged if foreign papers would reproduce this letter. The officer who is acting for me in the Madras Hospital will extend a hearty welcome to any who still care to go there. I can only again express my regret if my own unavoidable change of plans has caused inconvenience to others, and my hope that by giving as early notice as possible I have been able to minimise such inconvenience.

I am, Sir, yours faithfully,

R. H. EmLIOT, Lieut.COol. I.M.S.

London, W., Sept. 30th, 1913. Superintendent of the Hospital. 